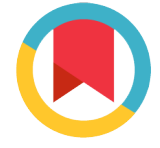

Check for updates
*For correspondence:

alesaleh70@yahoo.com

Competing interests: The authors declare that no competing interests exist.

Received: 26 August 2017 Accepted: 20 September 2017 Published: 14 October 2017

Copyright The Author(s) 2017. This article is published with open access by BioMedPress.

This article is distributed under the terms of the Creative Commons Attribution License (CC-BY 4.0) which permits any use, distribution, and reproduction in any medium, provided the original author(s) and the source are credited.

\section{Colorectal cancer in the world: incidence, mortality and risk factors}

\section{Hamidreza Sadeghi Gandomani1,2, Seyed Majid yousefi3, Mohammad Aghajani ${ }^{4}$, Abdollah Mohammadian-Hafshejani ${ }^{5}$, Abed Asgari Tarazoj6, Vahideh Pouyesh7, Hamid Salehiniya ${ }^{1,8}$}

\author{
1Zabol university of Medical Sciences, Zabol, Iran \\ ${ }^{2}$ Trauma Nursing Research Center, School of nursing and midwifery, Kashan University of \\ Medical Sciences, Kashan, Iran \\ ${ }^{3}$ Trauma Nursing Research Center, School of nursing and midwifery, Kashan University of \\ Medical Sciences, Kashan, Iran \\ ${ }^{4}$ Infections Diseases Research Center, Department of Nursing and Midwifery, Kashan \\ University of Medical Sciences, Kashan, Iran \\ ${ }^{5}$ Department of Public Health, School of Public Health, Dezful University of Medical \\ Sciences, Dezful, Iran \\ ${ }^{6}$ Department Of Nursing, College of Nursing, Naragh Branch, Islamic Azad University, \\ Naragh, Iran \\ ${ }^{7}$ Department of Nursing, Faculty of Nursing and Midwifery, Iranshahr University of \\ Medical Sciences, Sistan and Baluchestan, Iran \\ ${ }^{8}$ Department of Epidemiology and Biostatistics, Tehran University of medical sciences, \\ Tehran, Iran
}

\section{Abstract}

A rapid literature search strategy was conducted for all English language literature published before July 2017. The search was conducted using the electronic databases PubMed, Scopus and Web of Science. The search strategy included the keywords 'colorectal cancer', 'epidemiology', 'incidence', 'mortality', 'risk factor', and 'world'. In 2012, the highest CRC incidence rates were observed in the Republic of Korea, Slovakia and Hungary while the lowest incidence rates were seen in Singapore, Serbia and Japan. The highest CRC mortality rates in both sexes were seen in Central and Eastern Europe and the lowest mortality rates were found in Middle Division of Africa. The main risk factors for CRC include nutritional factors, past medical history, smoking, socioeconomic status, and family medical history. According to the increasing trend of CRC incidence and mortality in the world, implementation of prevention programs such as screening programs, diet modification, and healthy lifestyle education is necessary. 


\section{Keywords}

Colorectal Cancer, Incidence, Mortality, Risk Factors, Worldwide

\section{Introduction}

Colorectal cancer (CRC) is one of the leading causes of mortality and morbidity in the world (Favoriti et al., 2016). It is the third most common malignancy and the fourth leading cause of cancer-related deaths worldwide, accounting for approximately 1,400,000 new cases and about 700,000 deaths worldwide (Arnold et al., 2016). In recent decades there has been a significant increase in the incidence of CRC; in particular, the number of newly diagnosed CRC cases has increased from 783,000 in 1990 to 1,361,000 in 2012 (Ferlay et al., 2015a; Rafiemanesh et al., 2016). In terms of geographical distribution, this cancer has risen in industrialized countries with moderate and high Human Development Index (HDI) (Dolatkhah et al., 2015). In recent years, the incidence and mortality rates of CRC in Eastern Europe, Latin America and Asia have grown higher than other countries (Center et al., 2009a). The incidence and mortality rates of CRC in the countries with the highest HDI, such as certain Western European countries and the United States, have steadily decreased (Arnold et al., 2016).

It seems that familiarity with preventive measures, advances in therapeutic and diagnostic procedures (such as polypectomy), improvements in quality of preoperative assessment, and treatments (such as radiotherapy and chemotherapy) have played significant roles in reducing this trend (Center et al., 2009b; Murphy et al., 2015). With respect to gender, despite the prevalence of CRC in both sexes it was higher in men than in women (Ferlay et al., 2015a). Moreover, the risk of developing colorectal cancer increases with age. Indeed, more than $90 \%$ of diagnosed patients are over 50 years old and the average age of CRC diagnosis is 64 (Amersi et al., 2005). Also, significant geographical variations in the rate of $C R C$ incidence indicate that multiple factors can influence the increase in CRC rates. While most studies in this area have focused mainly on therapies for CRC (Alberts et al., 2005; Saltz et al., 2008), it is equally important to understand the epidemiological aspects of CRC. Indeed, comprehensive studies and analysis of the epidemiology and etiology of CRC are rare though essential. Therefore, this study aims to investigate the incidence rate, mortality rate and risk factors of CRC throughout the world. 


\section{Methods}

A rapid literature search strategy was conducted for all English language literature published before July 2017. The search was conducted using the following electronic databases: PubMed, Scopus and Web of Science. The search strategy included the following keywords: 'colorectal cancer', 'epidemiology', 'incidence', 'mortality', 'risk factor', and 'world'. The search strategy was adjusted according to different requirements for each database. The specific search was also performed in cancer-related websites for Iranrelated information.

\section{Results}

\section{Incidence rate}

The incidence rate of CRC varies greatly worldwide (Arnold et al., 2016). In 2012, the highest incidence rates of CRC were found in the Republic of Korea ( $A G R=$ 45) (Jung et al., 2015), Slovakia (AGR = 42.7) (Ferlay et al., 2013), Hungary (AGR $=42.3$ ) (Torre et al., 2015), Denmark (AGR $=40.5)$, and Netherlands ( $A G R=40.2$ per 100,000) (Ferlay et al., 2013). The lowest incidence rates were seen in Singapore ( $A G R=33.7)$, Spain $(A G R=33.1)$, Coatia $(A G R=32.9)$, Serbia (AGR = 32.6) and Japan ( $A G R=32.2$ per 100,000) (Ferlay et al., 2015b). CRC incidence in developing countries has been steadily increasing (Jemal et al., 2010). The highest increase was recorded in Western Asia (including Israel and Kuwait) and in Eastern Europe (Czech Republic, Slovakia and Slovenia) (Center et al., 2009a; Center et al., 2009b; Martín et al., 2008).

This increase indicates a growth in the prevalence of CRC risk factors associated with the Western lifestyle, such as unhealthy diet, obesity and tobacco consumption (Favoriti et al., 2016). In most parts of the world, the incidence rate of CRC was higher in men than in women (Torre et al., 2015). The causes of this difference may be due to the complex relationship between the exposure of men to certain risk factors and the different cancer screening tests for men and women (Brown et al., 2005; Meissner et al., 2006). The incidence rate of CRC increases with age (Boyle and Langman, 2000) and increases significantly among the age group of 40-50 years. CRC incidence rates will continue to rise in the coming decades (Ahnen and Macrae, 2010).

\section{Mortality rate}

In 2012, about 693,099 CRC deaths were recorded worldwide, accounting for 8\% of all cancer deaths (Ferlay et al., 2015b; Torre et al., 2015). In 2015, CRC was recognized as the third leading cause of cancer-related deaths with 49,700 diagnosed cases $(26,100$ cases in men and 23,600 in women) (Siegel et al., 2015). Colorectal cancer, indeed, is the fourth leading cause of cancer-related 
deaths in men and the third leading cause among women worldwide. The mortality rates vary according to each nation's HDI. As an example, the highest mortality rate is observed in countries with high HDls; these counties include those of Central and Eastern Europe and of Latin America (Favoriti et al., 2016). The highest mortality rates in both sexes was observed in Central and Eastern Europe (ASR $=20.3$ in men and 12.1 in women, per 100,000). The lowest mortality rates were seen in the Middle Division of Africa (ASR $=3.5$ and 2.7, per 100,000, in men and women, respectively) (Center et al., 2009a).

Mortality rates have shown a downward trend in most economically-developed countries (e.g. United States, Australia and New Zealand), most Western European countries (e.g. France, Germany and Spain), some Asian countries (e.g. Japan), Eastern European countries (e.g. Czech Republic, Latvia and Slovakia), and South Africa. The decrease in mortality could be due to improved diagnostic procedures, prevention and reduction of risk factors, and access to healthy diets (Bosetti et al., 2011; Edwards et al., 2010). However, the CRC mortality rate is still high in some countries with limited resources (such as Mexico, Brazil, Chile, Romania and Central America) (Center et al., 2009a; Chatenoud et al., 2014). The increase in mortality rate could be due to the lack of predictive measures and/or an increase in the incidence of CRC (Jung et al., 2015). Between 2001 and 2010, mortality rates decreased in both sexes by 3\% per year (Siegel et al., 2015). With regard to gender, the mortality rate in men is $30-40 \%$ higher than in women. In terms of race, the mortality rate in U.S. blacks (29.4 per 100000) is approximately 50\% higher than in whites (Favoriti et al., 2016). Moreover, the environmental factors and the delay in performing screening tests could be contributing factors to the observed differences (Potosky et al., 2002; Wang et al., 2012).

\section{Risk factors}

\section{Nutritional factors}

\section{Intake of fruits, vegetables and high-fiber diet}

Several epidemiological studies have shown an association between increased consumption of fruits and vegetables and reduced risk of CRC (Slattery et al., 1998; Terry et al., 2001). Fruit and vegetables appear to have a protective effect against CRC due to the richness of fiber, folic acid, antioxidants and vitamins (Negri et al., 1998; Willett et al., 1990). Several epidemiological and laboratory studies have confirmed the role of dietary fiber in the pathogenesis of CRC (Ahnen and Macrae, 2010). Several observational studies have reported a correlation between intake of a high-fiber diet and reduced risk of CRC (Bingham et al., 2003; Larsson et al., 2005a; Peters et al., 2003). The findings of a meta-analysis study also indicated that a high-fiber diet could reduce CRC incidence by up to $50 \%$ (Trock et al., 1990). A diet rich in fiber can reduce the 
risk of $C R C$ by lowering the $\mathrm{pH}$ of the sigmoid colon, reducing the colon transit time, and increasing the uptake of folic acid and micronutrients (such as antioxidants) in vegetables (Kritchevsky, 1995; Rex et al., 2009).

\section{High consumption of red meat and saturated fats}

Increased consumption of meats, animal fats, and cholesterol-rich foods are associated with an increased risk of CRC (Chao et al., 2005). The findings of a longitudinal study showed that CRC risk is significantly higher in people who eat more than 160 grams of processed meat every day (Norat et al., 2005). Another study also found that people who eat red meat more than five times a week were three times more likely to develop CRC than others (Wei et al., 2004). Indeed, the risk of CRC increases after high meat consumption due to stimulation of insulin secretion, increased iron absorption (heme), and increased fat intake (Gerhardsson de Verdier et al., 1991). Moreover, longer cooking time of meats increases heterocyclic amine production, which can also contribute to the increase in CRC incidence (Anderson, 2011; Martínez et al., 2007). Studies have found that after controlling variables (such as intake of vegetables and fruits), the risk of CRC incidence in people receiving a cholesterol-rich diet was significantly higher in comparison to those who consumed lower cholesterol levels (Järvinen et al., 2001; Lin, 2009).

\section{Alcohol Consumption}

With respect to alcohol consumption and CRC risk, a positive association between alcohol consumption and CRC incidence has been reported in several studies (Fedirko et al., 2011; Longnecker et al., 1990). Ethanol-containing beverages increase the risk of CRC incidence by producing carcinogenic substances and creating changes in bile acid compositions (Choi et al., 1999; Kune and Vitetta, 1992). The American Cancer Society has reported that an increase in alcohol consumption (more than 30 grams per day of ethanol) in men is associated with an increased risk of CRC incidence (Marmot et al., 2007). A Cohort study on 18,707 Korean adults after 11 years of follow-up showed that alcohol consumption was associated with an increased risk of CRC development among men. Also, the increase in duration and amount of alcohol consumption is directly related to the increase in CRC incidence (Shrubsole et al., 2008). The Health Professionals Follow-Up Study (HPFS) findings suggest that there is a positive relationship between alcohol consumption in men and CRC risk (Thygesen et al., 2008). The European Prospective Investigation into Cancer (EPIC) findings also showed that even after controlling for variables (such as smoking), an increase in alcohol drinking still increases the risk of CRC (Ferrari et al., 2007). The meta-analysis study also found that CRC risk was significantly increased in people who consume alcohol more frequently than twice a day (Cho et al., 2004). 


\section{Caffeine}

The relationship between caffeine consumption and CRC incidence has not been confirmed definitively (Lin, 2009). Although the findings of a meta-analysis of evidence-based studies revealed that there was a correlation between caffeine consumption and increased risk of CRC (Giovannucci et al., 1994), the NHS and HPFS findings did not prove this claim (Michels et al., 2000).

\section{Past medical history}

\section{Diabetes mellitus (DM)}

Various studies have shown that diabetes mellitus (DM) subjects are at risk for CRC compared to non-DM subjects (Hu et al., 1999; Will et al., 1998). Analysis of this cohort study, which lasted for 9 years on 484,020 individuals aged 71-50, showed that 7,598 cases were diagnosed with CRC. After controlling for nonnutritional confounders, it was found that DM was associated with an increased risk of CRC. Modifications and adaptations, in terms of dietary quality, did not affect the findings (Jarvandi et al., 2013). A meta-analysis study showed that the risk of CRC in people who have DM is 35\% higher than in non-DM subjects (Luo et al., 2016). The findings of the Nurses' Health Study (NHS) study showed a direct relationship between CRC incidence and DM diagnosis (Hu et al., 1999). The increase of insulin concentration and insulin-like growth factor (IGF)-1 levels, increase of glucose (hyperglycemia), and prolonged exposure of the colorectal mucosa to fecal bile acids (due to constipation) all play an important role in colorectal carcinogenesis (Airley and Mobasheri, 2007; Giovannucci, 2001a; Stadler et al., 1988). Also, hyperglycemia (Jee et al., 2005; Nilsen and Vatten, 2001; Saydah et al., 2003), hyperinsulinemia (Ma et al., 2004), and increased serum levels of IGF-1 (Wei et al., 2005) can cause the development of colorectal tumors (Grimberg and Cohen, 2000; Tran et al., 1996). Carcinogenesis caused by insulin resistance also leads to increased cell proliferation and reduced apoptosis (Grimberg and Cohen, 2000; Gunter and Leitzmann, 2006; Sandhu et al., 2002).

\section{Inflammatory bowel disease (IBD)}

Patients with long-term inflammatory bowel disease (IBD) have an increased risk of CRC. In fact, CRC accounts for $1 / 6^{\text {th }}$ of ulcerative colitis (UC)related deaths and $1 / 12^{\text {th }}$ of all deaths in patients with Crohn's disease (Jess et al., 2005; Jess et al., 2012). In UC, the risk of developing CRC depends on the duration and extent of disease. According to a study conducted in the United States, the highest risk was reported in patients with UC or pancolitis with a standardized incidence ratio of 2.4 (Jess et al., 2006). Findings of another study confirmed that CRC risk increases 8 - 10 years after the onset of UCrelated symptoms, compared to the control group matched by other variables (Rutter et al., 2006). Generally, the cumulative incidence of CRC in patients with UC has an increasing trend. For instance, at 20,30 and 35 years after diagnosis of UC, the percentage of UC-diagnosed patients afflicted with CRC was 5-10\%, 
12-20\%, and 30\%, respectively (Ekbom et al., 1990; Gyde et al., 1988). There are other factors that may be associated with the risk of developing CRC in patients with IBD. For example, the risk of developing CRC increases with early onset of primary disease (before age 15) (Gupta et al., 2007). The severity of inflammation is also a key factor which increases the risk of CRC (Rubin et al., 2013).

\section{Cholecystectomy}

Several studies have been reported the association between cholecystectomy and right-sided colon cancer (Vernick and Kuller, 1982; Vernick et al., 1980). The results of a study showed that patients undergoing cholecystectomy experienced a slight increase in right-sided colon cancer (with a standardized incidence ratio of 1.16 ) but no left-sided colon cancer was observed among them (Lagergren et al., 2001). The cohort study also found that the risk of CRC occurrence is increased by cholecystectomy (Schernhammer et al., 2003). Findings of another study also indicate that cholecystectomy is associated with an increased risk for colon cancer (Shao and Yang, 2005). Abnormal bile duct metabolism increases the gallstone formation, leading to an increased risk of CRC. Moreover, the fecal fat level increases after cholecystectomy (Goldacre et al., 2005). Constant colon exposure to high levels of metabolic products such as bile acids, non-digestible fat, and other end-products of colonic micro flora (like methylindole and zuccato) can lead to an increased risk of CRC (Ono et al., 2013).

\section{Ureterocolic Anastomosis}

A few studies have clearly reported an increase in the risk of colorectal neoplasia near the site of ureterocolic anastomosis after extensive urethral or intestinal tract surgery (Planning; Tollefson et al., 2010). The mechanism of this risk factor (which can lead to CRC) is the exposure of colonic mucosa to urinary-bladder carcinogens (Lin, 2009).

\section{Pelvic radiotherapy}

In patients with a history of pelvic radiotherapy, the risk of CRC occurrence is very high at 5 to 10 years after radiotherapy (Felder and Rogge, 1983; Sandler and Sandler, 1983). The findings of a retrospective study showed that the risk of developing $\mathrm{CRC}$ in patients with a history of radiation therapy for prostate cancer is higher than others (Baxter et al., 2005).

\section{Other Factors}

\section{Physical Activity and Obesity}

Reduced physical activity has been associated with an increased risk of CRC (Lee et al., 2012; Meyerhardt et al., 2006). The findings of a case-control study in North California indicated that decreased physical activity and increased body 
mass index (BMI) can significantly increase the risk of CRC (Slattery et al., 1997). The Cancer Prevention Study (CPS-II) findings also showed that there is a significant inverse association between physical activity and the risk of CRC (Thun et al., 1992). Findings of another study indicated that CRC risk is significantly higher in idle workers compared to workers who had light or heavy physical activity (Colbert et al., 2001). Daily inactivity can increase the incidence of obesity, which is another risk factor for CRC (Bardou et al., 2013). The precise mechanism of the protective effect of physical activity is still unclear, but it seems that physical activity lowers the risk of $\mathrm{CRC}$ by reducing $\mathrm{BMI}$, reducing the colonic transit time, and lowering insulin levels (Gribovskaja-Rupp et al., 2011; Mao et al., 2003). Obesity increases serum leptin levels (Frezza et al., 2006); leptin leads to CRC development (Sierra-Honigmann et al., 1998). Indeed, leptin enhances the growth and proliferation of colon cancer cells (Liu et al., 2001). It also increases the spread of adenomatous lesions in mouse studies (Hirose et al., 2004). Findings from a study showed that men with the highest serum leptin levels are twice more likely to develop CRC than men with the lowest serum leptin levels (Stattin et al., 2003). Obesity is one of the main risk factors for type 2 diabetes, which incidentally is one of the independent risk factors for CRC (Larsson et al., 2005b). This association is stronger in men than in women (Inoue et al., 2006). Obesity also increases insulin resistance and hyper-insulinemia (Frezza et al., 2006). The impact of diabetes on CRC will be discussed separately.

\section{Tobacco consumption}

Tobacco consumption and cigarette smoking, particularly, are common risk factors for CRC in both genders (Giovannucci, 2004). Findings from a cohort study in Korea indicated that "Former Smokers" carried a higher CRC risk than "Never" smokers (Kim et al., 2006). Another study found that CRC risk is increased in people who have smoked over 45 years, while there was no relationship between the number of cigarette packs and the risk of CRC (Cho et al., 2015). Smoking accounts for $20 \%$ of all types of CRC in the United States (Giovannucci, 2001b). Several studies have also found that smoking increases the risk of CRC by up to $30 \%$ in smokers (Giovannucci et al., 1994; Newcomb et al., 1995; Paskett et al., 2007).

\section{Aspirin and nonsteroidal anti-inflammatory drugs (NSAIDs)}

Studies have shown that the use of aspirin and other nonsteroidal antiinflammatory drugs (NSAIDs) can play a role in CRC prevention (Chan et al., 2005; Cuzick et al., 2009; Dubé et al., 2007). Evidence suggest that a 30-40\% reduction in risk of adenoma and CRC may be attributable to aspirin (Din et al., 2010).

\section{Socioeconomic Status (SES)}

The low socioeconomic status has a direct relation with the increased risk of CRC. According to one study of 506,488 participants, 7,676 developed CRC. In 
the study, it was found that CRC rates were higher in people with lower education or of lower socioeconomic status than those living in affluent areas, even after adjusting for other risk factors (Doubeni et al., 2012a). This difference can be due to higher incidence of moderating risk factors in those areas (such as immobility, unhealthy diet, smoking and obesity) as well as low screening rates in the areas (Doubeni et al., 2012b; Klabunde et al., 2011).

\section{Family history and adenomatous polyps}

In $20 \%$ of CRC cases, at least one family member typically has been afflicted with CRC (Butterworth et al., 2006). In fact, $85 \%$ of the CRCs originate from adenocinoma, which accounts for adenomatous polyps (Dove-Edwin et al., 2005). Generally $70-90 \%$ colorectal cancers arise from adenomatous polyps. Polyps larger than $2 \mathrm{~cm}$ in diameter have a $50 \%$ chance of malignancy (Levin et al., 2008). The occurrence of colorectal carcinomas in populations with a prevalence of mucosal polyps is higher than others and the risk of cancer is closely related to the number of these polyps. The risk of cancer can be reduced by removing the preneoplastic lesions (Oberg et al., 2011).

\section{Gender and Race}

The role of gender in CRC development has not been determined definitively (Haggar and Boushey, 2009). Although in most studies it has been reported that $\mathrm{CRC}$ risk is higher in men than in women- due to the progression of colorectal neoplasia- the overall life-threatening risk of CRC in both sexes is numerically identical (Lin, 2009; Zisman et al., 2006). CRC occurrence has a 5-year delay in women, compared to men. For example, a woman's CRC risk at age 55 is equivalent to a man's CRC risk at age 50 (Lieberman, 2005). The findings of a meta-analysis study showed that the risk of CRC and advanced adenoma in men was twice that for women (Nguyen et al., 2009). However, the results from the Bressler et al. study suggest that women are more likely to be exposed to CRC than men after colonoscopy (Bressler et al., 2007). The right-sided colon cancer has been observed more in women; inversely, the left-sided colon cancer is mostly observed in men (Brenner et al., 2007). In general, more studies are needed to confirm the role of gender in the occurrence of CRC. The incidence and mortality rate of CRC for African Americans is higher (for both genders) than in whites (Shavers, 2007). It seems that the cause of this difference is related to the etiological factors, such as smoking, diabetes mellitus, and the use of screening and diagnostic tests in African Americans (Wong, 2010).

\section{Conclusion}

This study evaluates the incidence rate, mortality and risk factors for CRC, based on a review of studies conducted throughout the world. The results of our analysis indicate that most CRC risk factors are related to dietary and lifestyle 
factors and can be prevented. Due to the fact that prophylactic risk factors (such as high-fat diet, low fiber, obesity, inactivity and smoking) are major contributors to the incidence of CRC, a comprehensive planning- especially in high-risk groups- is needed to prevent these factors. Healthy lifestyle education programs and sports/recreational facilities are necessary to enhance physical activities and implement this comprehensive planning. Also, the risk factors investigated in this study are often extracted from descriptive cross-sectional, prospective, retrospective and retrospective case studies. Therefore, due to the effect of confounding variables it is necessary to carry out further studies, especially interventional studies and trials, in order to confirm these risk factors.

\section{Abbreviations}

BMI: Body Mass Index

CRC: Colorectal Cancer

DM: Diabetes Mellitus

EPIC: The European Prospective Investigation into Cancer

HDI: Human Development Index

HPFS: Health Professionals Follow-Up Study

IBD: Inflammatory Bowel Disease

IGF: Insulin-like growth factor

NHS: Nurses' Health Study

NSAIDs: Nonsteroidal Anti-inflammatory Drugs

SES: Socioeconomic Status

UC: Ulcerative Colitis

\section{Author Contributions}

All authors contributed to the design of the research. HSG, SMY, MA, AMH, AAT and AP extracted the data and summarized it. All authors drafted the first version. HSG, AMH and HS edited the first draft. All authors reviewed, commented and approved the final draft.

\section{References}

Ahnen DJ, Macrae F. Colorectal cancer: Epidemiology, risk factors, and protective factors. UpToDate Version. 2010;41.

Airley, R. E., \& Mobasheri, A. (2007). Hypoxic regulation of glucose transport, anaerobic metabolism and angiogenesis in cancer: Novel pathways and targets for anticancer therapeutics. Chemotherapy, 53(4), 233-256. https://doi.org/10.1159/000104457 
Alberts, S. R., Horvath, W. L., Sternfeld, W. C., Goldberg, R. M., Mahoney, M. R., Dakhil, S. R., ... Donohue, J. H. (2005). Oxaliplatin, fluorouracil, and leucovorin for patients with unresectable liver-only metastases from colorectal cancer: A North Central Cancer Treatment Group phase II study. Journal of Clinical Oncology, 23(36), 9243-9249. https://doi.org/10.1200/JCO.2005.07.740

Amersi, F., Agustin, M., \& Ko, C. Y. (2005). Colorectal cancer: Epidemiology, risk factors, and health services. Clinics in Colon and Rectal Surgery, 18(3), 133-140. https:// doi.org/10.1055/s-2005-916274

Anderson, J. C. (2011). Risk factors and screening for colorectal cancer. Colorectal Cancer Screening (pp. 7-23). Springer. https://doi.org/10.1007/978-1-60761-398-5_2

Arnold M, Sierra MS, Laversanne M, Soerjomataram I, Jemal A, Bray F. Global patterns and trends in colorectal cancer incidence and mortality. Gut. 2016:gutjnl-2015-310912.

Bardou, M., Barkun, A. N., \& Martel, M. (2013). Obesity and colorectal cancer. Gut, 62(6), 933-947. https://doi.org/10.1136/gutjnl-2013-304701

Baxter, N. N., Tepper, J. E., Durham, S. B., Rothenberger, D. A., \& Virnig, B. A. (2005). Increased risk of rectal cancer after prostate radiation: A population-based study. Gastroenterology, 128(4), 819-824. https://doi.org/10.1053/j.gastro.2004.12.038

Bingham, S. A., Day, N. E., Luben, R., Ferrari, P., Slimani, N., Norat, T., ... Riboli, E., \& the European Prospective Investigation into Cancer and Nutrition. (2003). Dietary fibre in food and protection against colorectal cancer in the European Prospective Investigation into Cancer and Nutrition (EPIC): An observational study. Lancet, 361(9368), 1496-1501. https://doi.org/10.1016/S0140-6736(03)13174-1

Bosetti, C., Levi, F., Rosato, V., Bertuccio, P., Lucchini, F., Negri, E., \& La Vecchia, C. (2011). Recent trends in colorectal cancer mortality in Europe. International Journal of Cancer, 129(1), 180-191. https://doi.org/10.1002/ijc.25653

Boyle, P., \& Langman, J. S. (2000). ABC of colorectal cancer: Epidemiology. BMJ: British Medical Journal., 321(7264), 805-808. https://doi.org/10.1136/bmj.321.7264.805

Brenner, H., Hoffmeister, M., Arndt, V., \& Haug, U. (2007). Gender differences in colorectal cancer: Implications for age at initiation of screening. British Journal of Cancer, 96(5), 828-831. https://doi.org/10.1038/sj.bjc.6603628

Bressler, B., Paszat, L. F., Chen, Z., Rothwell, D. M., Vinden, C., \& Rabeneck, L. (2007). Rates of new or missed colorectal cancers after colonoscopy and their risk factors: A population-based analysis. Gastroenterology, 132(1), 96-102. https://doi.org/10.1053/ j.gastro.2006.10.027

Brown, D. W., Young, K. E., Anda, R. F., \& Giles, W. H. (2005). Asthma and risk od death from lung cancer. The Journal of Asthma, 42(3), 597-600.

Butterworth, A. S., Higgins, J. P., \& Pharoah, P. (2006). Relative and absolute risk of colorectal cancer for individuals with a family history: A meta-analysis. European Journal of Cancer, 42(2), 216-227. https://doi.org/10.1016/j.ejca.2005.09.023

Center, M. M., Jemal, A., \& Ward, E. (2009). International trends in colorectal cancer incidence rates. Cancer Epidemiology and Prevention Biomarkers., 18(6), 1688-1694. https://doi.org/10.1158/1055-9965.EPI-09-0090

Center, M. M., Jemal, A., Smith, R. A., \& Ward, E. (2009). Worldwide variations in colorectal cancer. CA: a Cancer Journal for Clinicians, 59(6), 366-378. https://doi.org/ $\underline{10.3322 / \mathrm{caac} .20038}$ 
Chan, A. T., Giovannucci, E. L., Meyerhardt, J. A., Schernhammer, E. S., Curhan, G. C., \& Fuchs, C. S. (2005). Long-term use of aspirin and nonsteroidal anti-inflammatory drugs and risk of colorectal cancer. Journal of the American Medical Association, 294(8), 914923. https://doi.org/10.1001/jama.294.8.914

Chao, A., Thun, M. J., Connell, C. J., McCullough, M. L., Jacobs, E. J., Flanders, W. D., . . Calle, E. E. (2005). Meat consumption and risk of colorectal cancer. Journal of the American Medical Association, 293(2), 172-182. https://doi.org/10.1001/jama. 293.2.172

Chatenoud, L., Bertuccio, P., Bosetti, C., Malvezzi, M., Levi, F., Negri, E., \& La Vecchia, C. (2014). Trends in mortality from major cancers in the Americas: 1980-2010. Annals of Oncology: Official Journal of the European Society for Medical Oncology, 25(9), 18431853. https://doi.org/10.1093/annonc/mdu206

Cho, E., Smith-Warner, S. A., Ritz, J., van den Brandt, P. A., Colditz, G. A., Folsom, A. R., ... Hunter, D. J. (2004). Alcohol intake and colorectal cancer: A pooled analysis of 8 cohort studies. Annals of Internal Medicine, 140(8), 603-613. https://doi.org/ 10.7326/0003-4819-140-8-200404200-00007

Cho, S., Shin, A., Park, S. K., Shin, H.-R., Chang, S.-H., \& Yoo, K.-Y. (2015). Alcohol drinking, cigarette smoking and risk of colorectal cancer in the Korean multi-center cancer cohort. Journal of Cancer Prevention, 20(2), 147-152. https://doi.org/10.15430/ JCP.2015.20.2.147

Choi, S.-W., Stickel, F., Baik, H. W., Kim, Y.-I., Seitz, H. K., \& Mason, J. B. (1999). Chronic alcohol consumption induces genomic but not p53-specific DNA hypomethylation in rat colon. The Journal of Nutrition, 129(11), 1945-1950.

Colbert, L. H., Hartman, T. J., Malila, N., Limburg, P. J., Pietinen, P., Virtamo, J., . . . Albanes, D. (2001). Physical activity in relation to cancer of the colon and rectum in a cohort of male smokers. Cancer Epidemiology and Prevention Biomarkers., 10(3), 265268.

Cuzick, J., Otto, F., Baron, J. A., Brown, P. H., Burn, J., Greenwald, P., ... Thun, M. (2009). Aspirin and non-steroidal anti-inflammatory drugs for cancer prevention: An international consensus statement. The Lancet. Oncology, 10(5), 501-507. https:// doi.org/10.1016/S1470-2045(09)70035-X

Din, F. V., Theodoratou, E., Farrington, S. M., Tenesa, A., Barnetson, R. A., Cetnarskyj, R., . . Dunlop, M. G. (2010). Effect of aspirin and NSAIDs on risk and survival from colorectal cancer. Gut, 59(12), 1670-1679. https://doi.org/10.1136/gut.2009.203000

Dolatkhah, R., Somi, M. H., Kermani, I. A., Ghojazadeh, M., Jafarabadi, M. A., Farassati, F., \& Dastgiri, S. (2015). Increased colorectal cancer incidence in Iran: A systematic review and meta-analysis. BMC Public Health, 15(1), 997. https://doi.org/10.1186/ s12889-015-2342-9

Doubeni, C. A., Laiyemo, A. O., Major, J. M., Schootman, M., Lian, M., Park, Y., ... Sinha, R. (2012). Socioeconomic status and the risk of colorectal cancer: An analysis of more than a half million adults in the National Institutes of Health-AARP Diet and Health Study. Cancer, 118(14), 3636-3644. https://doi.org/10.1002/cncr.26677

Doubeni, C. A., Major, J. M., Laiyemo, A. O., Schootman, M., Zauber, A. G., Hollenbeck, A. R., . . Allison, J. (2012). Contribution of behavioral risk factors and obesity to socioeconomic differences in colorectal cancer incidence. Journal of the National Cancer Institute, 104(18), 1353-1362. https://doi.org/10.1093/jnci/djs346 
Dove-Edwin, I., Sasieni, P., Adams, J., \& Thomas, H. J. (2005). Prevention of colorectal cancer by colonoscopic surveillance in individuals with a family history of colorectal cancer: 16 year, prospective, follow-up study. BMJ (Clinical Research Ed.), 331(7524), 1047. https://doi.org/10.1136/bmj.38606.794560.EB

Dubé, C., Rostom, A., Lewin, G., Tsertsvadze, A., Barrowman, N., Code, C., .. Moher, D., \& the U.S. Preventive Services Task Force. (2007). The use of aspirin for primary prevention of colorectal cancer: A systematic review prepared for the U.S. Preventive Services Task Force. Annals of Internal Medicine, 146(5), 365-375. https://doi.org/ 10.7326/0003-4819-146-5-200703060-00009

Edwards, B. K. W. E., Ward, E., Kohler, B. A., Eheman, C., Zauber, A. G., Anderson, R. N., ... Ries, L. A. (2010). Annual report to the nation on the status of cancer, 1975-2006, featuring colorectal cancer trends and impact of interventions (risk factors, screening, and treatment) to reduce future rates. Cancer, 116(3), 544-573. https://doi.org/ $10.1002 /$ cncr. 24760

Ekbom, A., Helmick, C., Zack, M., \& Adami, H. O. (1990). Ulcerative colitis and colorectal cancer. A population-based study. Engl J Med., 323(18), 1228-1233. https://doi.org/ 10.1056/NEJM199011013231802

Erlay J, Ervik M, Dikshit R, Eser S, Mathers C. Cancer incidence and mortality worldwide: IARC CancerBase No. 11. GLOBOCAN 2012 v1 02012.

Favoriti, P., Carbone, G., Greco, M., Pirozzi, F., Pirozzi, R. E. M., \& Corcione, F. (2016). Worldwide burden of colorectal cancer: A review. Updates in Surgery, 68(1), 7-11. https://doi.org/10.1007/s13304-016-0359-y

Fedirko, V., Tramacere, I., Bagnardi, V., Rota, M., Scotti, L., Islami, F., ... Jenab, M. (2011). Alcohol drinking and colorectal cancer risk: An overall and dose-response metaanalysis of published studies. Annals of Oncology : Official Journal of the European Society for Medical Oncology, 22(9), 1958-1972. https://doi.org/10.1093/annonc/ mdq653

Felder, M., \& Rogge, H. (1983). Radiation-induced cancers of the colon and rectum: Assessing the risk. Innere Medizin, 10(4), 161-163.

Ferlay, J., Soerjomataram, I., Dikshit, R., Eser, S., Mathers, C., Rebelo, M., . . Bray, F. (2015). Cancer incidence and mortality worldwide: Sources, methods and major patterns in GLOBOCAN 2012. International Journal of Cancer, 136(5), E359-E386. https://doi.org/10.1002/ijc.29210

Ferlay, J., Steliarova-Foucher, E., Lortet-Tieulent, J., Rosso, S., Coebergh, J. W., Comber, H., ... Bray, F. (2013). Cancer incidence and mortality patterns in Europe: Estimates for 40 countries in 2012. European Journal of Cancer, 49(6), 1374-1403. https://doi.org/ 10.1016/j.ejca.2012.12.027

Ferrari, P., Jenab, M., Norat, T., Moskal, A., Slimani, N., Olsen, A., . . Riboli, E. (2007). Lifetime and baseline alcohol intake and risk of colon and rectal cancers in the European prospective investigation into cancer and nutrition (EPIC). International Journal of Cancer, 121(9), 2065-2072. https://doi.org/10.1002/ijc.22966

Frezza, E. E., Wachtel, M. S., \& Chiriva-Internati, M. (2006). Influence of obesity on the risk of developing colon cancer. Gut, 55(2), 285-291. https://doi.org/10.1136/gut. 2005.073163

Gerhardsson de Verdier, M., Hagman, U., Peters, R. K., Steineck, G., \& Övervik, E. (1991). Meat, cooking methods and colorectal cancer: A case-referent study in Stockholm. 
International Journal of Cancer, 49(4), 520-525. https://doi.org/10.1002/ijc. 2910490408

Giovannucci, E. (1998). Meta-analysis of coffee consumption and risk of colorectal cancer. American Journal of Epidemiology, 147(11), 1043-1052. https://doi.org/ 10.1093/oxfordjournals.aje.a009398

Giovannucci, E. (2001). An updated review of the epidemiological evidence that cigarette smoking increases risk of colorectal cancer. Cancer Epidemiology and Prevention Biomarkers., 10(7), 725-731.

Giovannucci, E. (2001). Insulin, insulin-like growth factors and colon cancer: A review of the evidence. The Journal of Nutrition, 131(11, Suppl), 3109S-3120S.

Giovannucci, E. (2004). Should smokers be considered a high-risk group for colorectal cancer? Digestive and Liver Disease, 36(10), 643-645. https://doi.org/10.1016/j.dld. 2004.06.012

Giovannucci, E., Rimm, E. B., Stampfer, M. J., Colditz, G. A., Ascherio, A., Kearney, J., \& Willett, W. C. (1994). A prospective study of cigarette smoking and risk of colorectal adenoma and colorectal cancer in U.S. men. Journal of the National Cancer Institute, 86(3), 183-191. https://doi.org/10.1093/jnci/86.3.183

Goldacre, M. J., Abisgold, J. D., Seagroatt, V., \& Yeates, D. (2005). Cancer after cholecystectomy: Record-linkage cohort study. British Journal of Cancer, 92(7), 13071309. https://doi.org/10.1038/sj.bjc.6602392

Gribovskaja-Rupp, I., Kosinski, L., \& Ludwig, K. A. (2011). Obesity and colorectal cancer. Clinics in Colon and Rectal Surgery, 24(4), 229-243. https://doi.org/10.1055/ $\underline{\mathrm{s}-0031-1295686}$

Grimberg, A., \& Cohen, P. (2000). Role of insulin-like growth factors and their binding proteins in growth control and carcinogenesis. Journal of Cellular Physiology, 183(1), 1 9. https://doi.org/10.1002/(SICI)1097-4652(200004)183:1<1::AID-JCP1>3.0.CO;2-J

Gunter, M. J., \& Leitzmann, M. F. (2006). Obesity and colorectal cancer: Epidemiology, mechanisms and candidate genes. The Journal of Nutritional Biochemistry, 17(3), 145156. https://doi.org/10.1016/j.jnutbio.2005.06.011

Gupta, R. B., Harpaz, N., Itzkowitz, S., Hossain, S., Matula, S., Kornbluth, A., ... Ullman, T. (2007). Histologic inflammation is a risk factor for progression to colorectal neoplasia in ulcerative colitis: A cohort study. Gastroenterology, 133(4), 1099-1105. https://doi.org/ 10.1053/j.gastro.2007.08.001

Gyde, S. N. P. P., Prior, P., Allan, R. N., Stevens, A., Jewell, D. P., Truelove, S. C., ... Hellers, G. (1988). Colorectal cancer in ulcerative colitis: A cohort study of primary referrals from three centres. Inflammatory Bowel Diseases, 29(2), 206-217. https://doi.org/ 10.1136/gut.29.2.206

Haggar, F. A., \& Boushey, R. P. (2009). Colorectal cancer epidemiology: Incidence, mortality, survival, and risk factors. Clinics in Colon and Rectal Surgery, 22(4), 191-197. https://doi.org/10.1055/s-0029-1242458

Hirose, Y., Hata, K., Kuno, T., Yoshida, K., Sakata, K., Yamada, Y., . . Mori, H. (2004). Enhancement of development of azoxymethane-induced colonic premalignant lesions in C57BL/KsJ-db/db mice. Carcinogenesis, 25(5), 821-825. https://doi.org/10.1093/ carcin/bgh059

Hu, F. B., Manson, J. E., Liu, S., Hunter, D., Colditz, G. A., Michels, K. B., ... Giovannucci, E. (1999). Prospective study of adult onset diabetes mellitus (type 2) and risk of 
colorectal cancer in women. Journal of the National Cancer Institute, 91(6), 542-547. https://doi.org/10.1093/jnci/91.6.542

Inoue, M., Iwasaki, M., Otani, T., Sasazuki, S., Noda, M., \& Tsugane, S. (2006). Diabetes mellitus and the risk of cancer: Results from a large-scale population-based cohort study in Japan. Archives of Internal Medicine, 166(17), 1871-1877. https://doi.org/ 10.1001/archinte.166.17.1871

Jarvandi, S., Davidson, N. O., \& Schootman, M. (2013). Increased risk of colorectal cancer in type 2 diabetes is independent of diet quality. PLoS One, 8(9), e74616. https://doi.org/10.1371/journal.pone.0074616

Järvinen, R., Knekt, P., Hakulinen, T., Rissanen, H., \& Heliövaara, M. (2001). Dietary fat, cholesterol and colorectal cancer in a prospective study. British Journal of Cancer, 85(3), 357-361. https://doi.org/10.1054/bjoc.2001.1906

Jee, S. H., Ohrr, H., Sull, J. W., Yun, J. E., Ji, M., \& Samet, J. M. (2005). Fasting serum glucose level and cancer risk in Korean men and women. Journal of the American Medical Association, 293(2), 194-202. https://doi.org/10.1001/jama.293.2.194

Jemal, A., Center, M. M., DeSantis, C., \& Ward, E. M. (2010). Global patterns of cancer incidence and mortality rates and trends. Cancer Epidemiology and Prevention Biomarkers., 19(8), 1893-1907. https://doi.org/10.1158/1055-9965.EPI-10-0437

Jess, T., Gamborg, M., Matzen, P., Munkholm, P., \& Sørensen, T. I. (2005). Increased risk of intestinal cancer in Crohn's disease: A meta-analysis of population-based cohort studies. The American Journal of Gastroenterology, 100(12), 2724-2729. https:// doi.org/10.1111/j.1572-0241.2005.00287.x

Jess, T., Loftus, E. V., Jr., Velayos, F. S., Harmsen, W. S., Zinsmeister, A. R., Smyrk, T. C., .. . Sandborn, W. J. (2006). Risk of intestinal cancer in inflammatory bowel disease: A population-based study from olmsted county, Minnesota. Gastroenterology, 130(4), 1039-1046. https://doi.org/10.1053/j.gastro.2005.12.037

Jess, T., Rungoe, C., \& Peyrin-Biroulet, L. (2012). Risk of colorectal cancer in patients with ulcerative colitis: A meta-analysis of population-based cohort studies. Clinical Gastroenterology and Hepatology, 10(6), 639-645. https://doi.org/10.1016/j.cgh. 2012.01.010

Jung K-W, Won Y-J, Kong H-J, Oh C-M, Cho H, Lee DH, et al. Cancer statistics in Korea: incidence, mortality, survival, and prevalence in 2012. Cancer research and treatment: official journal of Korean Cancer Association. 2015;47(2):127.

Kim HJ, Lee SM, Choi NK, Kim SH, Song HJ, Cho YK, et al. Smoking and colorectal cancer risk in the Korean elderly. Journal of preventive medicine and public health= Yebang Uihakhoe chi. 2006;39(2):123-9.

Klabunde C, Cronin KA, Breen N, Waldron WR, Ambs AH, Nadel M. Trends in colorectal cancer test use among vulnerable populations in the US. Cancer Epidemiology and Prevention Biomarkers. 2011:cebp. 0220.2011.

Kritchevsky, D. (1995). Epidemiology of fibre, resistant starch and colorectal cancer. European Journal of Cancer Prevention, 4(5), 345-352. https://doi.org/ 10.1097/00008469-199510000-00003

Kune, G. A., \& Vitetta, L. (1992). Alcohol consumption and the etiology of colorectal cancer: A review of the scientific evidence from 1957 to 1991. Nutrition and Cancer, 18(2), 97-111. https://doi.org/10.1080/01635589209514210 
Lagergren, J., Ye, W., \& Ekbom, A. (2001). Intestinal cancer after cholecystectomy: Is bile involved in carcinogenesis? Gastroenterology, 121(3), 542-547. https://doi.org/ 10.1053/gast.2001.27083

Larsson, S. C., Giovannucci, E., Bergkvist, L., \& Wolk, A. (2005). Whole grain consumption and risk of colorectal cancer: A population-based cohort of 60,000 women. British Journal of Cancer, 92(9), 1803-1807. https://doi.org/10.1038/sj.bjc. $\underline{6602543}$

Larsson, S. C., Orsini, N., \& Wolk, A. (2005). Diabetes mellitus and risk of colorectal cancer: A meta-analysis. Journal of the National Cancer Institute, 97(22), 1679-1687. https://doi.org/10.1093/jnci/dji375

Lee, I.-M., Shiroma, E. J., Lobelo, F., Puska, P., Blair, S. N., \& Katzmarzyk, P. T., \& the Lancet Physical Activity Series Working Group. (2012). Effect of physical inactivity on major non-communicable diseases worldwide: An analysis of burden of disease and life expectancy. Lancet, 380(9838), 219-229. https://doi.org/10.1016/ $\underline{\text { S0140-6736(12)61031-9 }}$

Levin, B., Lieberman, D. A., McFarland, B., Andrews, K. S., Brooks, D., Bond, J., . . . Winawer, S. J., \& the American Cancer Society Colorectal Cancer Advisory Group, \& the US Multi-Society Task Force, \& the American College of Radiology Colon Cancer Committee. (2008). Screening and surveillance for the early detection of colorectal cancer and adenomatous polyps, 2008: A joint guideline from the American Cancer Society, the US Multi-Society Task Force on Colorectal Cancer, and the American College of Radiology. Gastroenterology, 134(5), 1570-1595. https://doi.org/10.1053/ j.gastro.2008.02.002

Lieberman, D. (2005). Race, gender, and colorectal cancer screening. The American Journal of Gastroenterology, 100(12), 2756-2758. https://doi.org/10.1111/j. 1572-0241.2005.00352.x

Lin OS. Acquired risk factors for colorectal cancer. Cancer Epidemiology: Modifiable Factors. 2009:361-72. https://doi.org/10.1007/978-1-60327-492-0_16

Liu, Z., Uesaka, T., Watanabe, H., \& Kato, N. (2001). High fat diet enhances colonic cell proliferation and carcinogenesis in rats by elevating serum leptin. International Journal of Oncology, 19(5), 1009-1014.

Longnecker, M. P., Orza, M. J., Adams, M. E., Vioque, J., \& Chalmers, T. C. (1990). A meta-analysis of alcoholic beverage consumption in relation to risk of colorectal cancer. Cancer Causes \& Control, 1(1), 59-68. https://doi.org/10.1007/BF00053184

Luo $\mathrm{S}$ e. Diabetes mellitus increase the risk of colorectal neoplasia: an updated a metaanalysis. Clinics and research in hapathology and gastroenterology 2015;5(21): 1679-87.

Ma, J., Giovannucci, E., Pollak, M., Leavitt, A., Tao, Y., Gaziano, J. M., \& Stampfer, M. J. (2004). A prospective study of plasma C-peptide and colorectal cancer risk in men. Journal of the National Cancer Institute, 96(7), 546-553. https://doi.org/10.1093/jnci/ djh082

Mao, Y., Pan, S., Wen, S. W., \& Johnson, K. C., \& the Canadian Cancer Registries Epidemiology Research Group. (2003). Physical inactivity, energy intake, obesity and the risk of rectal cancer in Canada. International Journal of Cancer, 105(6), 831-837. https://doi.org/10.1002/ijc.11159

Marmot M, Atinmo T, Byers T, Chen J, Hirohata T, Jackson A, et al. Food, nutrition, physical activity, and the prevention of cancer: a global perspective. 2007. 
Martín, J. J. D., Hernández, L. S., Gonzalez, M. G., Mendez, C. P., Rey Galán, C., \& Guerrero, S. M. (2008). Trends in childhood and adolescent obesity prevalence in Oviedo (Asturias, Spain) 1992-2006. Acta Paediatrica (Oslo, Norway), 97(7), 955-958. https://doi.org/10.1111/j.1651-2227.2008.00828.x

Martínez, M. E., Jacobs, E. T., Ashbeck, E. L., Sinha, R., Lance, P., Alberts, D. S., \& Thompson, P. A. (2007). Meat intake, preparation methods, mutagens and colorectal adenoma recurrence. Carcinogenesis, 28(9), 2019-2027. https://doi.org/10.1093/ carcin/bgm179

Meissner, H. I., Breen, N., Klabunde, C. N., \& Vernon, S. W. (2006). Patterns of colorectal cancer screening uptake among men and women in the United States. Cancer Epidemiology and Prevention Biomarkers., 15(2), 389-394. https://doi.org/ 10.1158/1055-9965.EPI-05-0678

Meyerhardt, J. A., Giovannucci, E. L., Holmes, M. D., Chan, A. T., Chan, J. A., Colditz, G. A., \& Fuchs, C. S. (2006). Physical activity and survival after colorectal cancer diagnosis. Journal of Clinical Oncology, 24(22), 3527-3534. https://doi.org/10.1200/JCO. $\underline{2006.06 .0855}$

Michels, K. B., Edward Giovannucci., Joshipura, K. J., Rosner, B. A., Stampfer, M. J., Fuchs, C. S., . . . Willett, W. C. (2000). Prospective study of fruit and vegetable consumption and incidence of colon and rectal cancers. Journal of the National Cancer Institute, 92(21), 1740-1752. https://doi.org/10.1093/jnci/92.21.1740

Murphy, C. C., Harlan, L. C., Lund, J. L., Lynch, C. F., \& Geiger, A. M. (2015). Patterns of colorectal cancer care in the United States: 1990-2010. JNCl. Journal of the National Cancer Institute, 107(10). https://doi.org/10.1093/jnci/djv198

Negri, E., Franceschi, S., Parpinel, M., \& La Vecchia, C. (1998). Fiber intake and risk of colorectal cancer. Cancer Epidemiology and Prevention Biomarkers., 7(8), 667-671.

Newcomb, P. A., Storer, B. E., \& Marcus, P. M. (1995). Cigarette smoking in relation to risk of large bowel cancer in women. Cancer Research, 55(21), 4906-4909.

Nguyen SP, Bent S, Chen Y-H, Terdiman JP. Gender as a risk factor for advanced neoplasia and colorectal cancer: a systematic review and meta-analysis. Clinical Gastroenterology and Hepatology. 2009;7(6):676-81. e3. https://doi.org/10.1016/j.cgh. $\underline{2009.01 .008}$

Nilsen, T. I., \& Vatten, L. J. (2001). Prospective study of colorectal cancer risk and physical activity, diabetes, blood glucose and BMI: Exploring the hyperinsulinaemia hypothesis. British Journal of Cancer, 84(3), 417-422. https://doi.org/10.1054/bjoc. 2000.1582

Norat, T., Bingham, S., Ferrari, P., Slimani, N., Jenab, M., Mazuir, M., . . Riboli, E. (2005). Meat, fish, and colorectal cancer risk: The European Prospective Investigation into cancer and nutrition. Journal of the National Cancer Institute, 97(12), 906-916. https:// doi.org/10.1093/jnci/dji164

Oberg, A. L., French, A. J., Sarver, A. L., Subramanian, S., Morlan, B. W., Riska, S. M., . . Thibodeau, S. N. (2011). miRNA expression in colon polyps provides evidence for a multihit model of colon cancer. PLoS One, 6(6), e20465. https://doi.org/10.1371/ journal.pone.0020465

Ono, K., Idani, H., Hidaka, H., Kusudo, K., Koyama, Y., \& Taguchi, S. (2013). Effect of aspirin continuation on blood loss and postoperative morbidity in patients undergoing laparoscopic cholecystectomy or colorectal cancer resection. Surgical Laparoscopy, 
Endoscopy \& Percutaneous Techniques, 23(1), 97-100. https://doi.org/10.1097/SLE. $\underline{0 \text { b013e318278cdf8 }}$

Paskett, E. D., Reeves, K. W., Rohan, T. E., Allison, M. A., Williams, C. D., Messina, C. R., ... Hunt, J. R. (2007). Association between cigarette smoking and colorectal cancer in the Women's Health Initiative. Journal of the National Cancer Institute, 99(22), 1729-1735. https://doi.org/10.1093/jnci/djm176

Peters, U., Sinha, R., Chatterjee, N., Subar, A. F., Ziegler, R. G., Kulldorff, M., ... Hayes, R. B., \& the Prostate, Lung, Colorectal, and Ovarian Cancer Screening Trial Project Team. (2003). Dietary fibre and colorectal adenoma in a colorectal cancer early detection programme. Lancet, 361(9368), 1491-1495. https://doi.org/10.1016/ S0140-6736(03)13173-X

Planning PF. Neoplasia after Ureterosigmoidostomy.

Potosky, A. L., Harlan, L. C., Kaplan, R. S., Johnson, K. A., \& Lynch, C. F. (2002). Age, sex, and racial differences in the use of standard adjuvant therapy for colorectal cancer. Journal of Clinical Oncology, 20(5), 1192-1202. https://doi.org/10.1200/JCO. 2002.20.5.1192

Rafiemanesh, H., Pakzad, R., Abedi, M., Kor, Y., Moludi, J., Towhidi, F., ... Salehiniya, H. (2016). Colorectal cancer in Iran: Epidemiology and morphology trends. EXCLI Journal, 15, 738-744.

Rex, D. K., Johnson, D. A., Anderson, J. C., Schoenfeld, P. S., Burke, C. A., \& Inadomi, J. M., \& the American College of Gastroenterology. (2009). American College of Gastroenterology guidelines for colorectal cancer screening 2009 [corrected]. The American Journal of Gastroenterology, 104(3), 739-750. https://doi.org/10.1038/ajg. $\underline{2009.104}$

Rubin DT, Huo D, Kinnucan JA, Sedrak MS, McCullom NE, Bunnag AP, et al. Inflammation is an independent risk factor for colonic neoplasia in patients with ulcerative colitis: a case-control study. Clinical Gastroenterology and Hepatology. 2013;11(12):1601-8. e4. https://doi.org/10.1016/j.cgh.2013.06.023

Rutter, M. D., Saunders, B. P., Wilkinson, K. H., Rumbles, S., Schofield, G., Kamm, M. A., . . . Forbes, A. (2006). Thirty-year analysis of a colonoscopic surveillance program for neoplasia in ulcerative colitis. Gastroenterology, 130(4), 1030-1038. https://doi.org/ 10.1053/j.gastro.2005.12.035

Saltz, L. B., Clarke, S., Díaz-Rubio, E., Scheithauer, W., Figer, A., Wong, R., . . Cassidy, J. (2008). Bevacizumab in combination with oxaliplatin-based chemotherapy as first-line therapy in metastatic colorectal cancer: A randomized phase III study. Journal of Clinical Oncology, 26(12), 2013-2019. https://doi.org/10.1200/JCO.2007.14.9930

Sandhu, M. S., Dunger, D. B., \& Giovannucci, E. L. (2002). Insulin, insulin-like growth factor-I (IGF-I), IGF binding proteins, their biologic interactions, and colorectal cancer. Journal of the National Cancer Institute, 94(13), 972-980. https://doi.org/10.1093/jnci/ 94.13.972

Sandler, R. S., \& Sandler, D. P. (1983). Radiation-induced cancers of the colon and rectum: Assessing the risk. Gastroenterology, 84(1), 51-57.

Saydah, S. H., Platz, E. A., Rifai, N., Pollak, M. N., Brancati, F. L., \& Helzlsouer, K. J. (2003). Association of markers of insulin and glucose control with subsequent colorectal cancer risk. Cancer Epidemiology and Prevention Biomarkers., 12(5), 412-418.

Schernhammer, E. S., Leitzmann, M. F., Michaud, D. S., Speizer, F. E., Giovannucci, E., Colditz, G. A., \& Fuchs, C. S. (2003). Cholecystectomy and the risk for developing 
colorectal cancer and distal colorectal adenomas. British Journal of Cancer, 88(1), 7983. https://doi.org/10.1038/sj.bjc.6600661

Shao, T., \& Yang, Y. X. (2005). Cholecystectomy and the risk of colorectal cancer. The American Journal of Gastroenterology, 100(8), 1813-1820. https://doi.org/10.1111/j. 1572-0241.2005.41610.x

Shavers, V. L. (2007). Racial/ethnic variation in the anatomic subsite location of in situ and invasive cancers of the colon. Journal of the National Medical Association, 99(7), 733-748.

Shrubsole, M. J., Wu, H., Ness, R. M., Shyr, Y., Smalley, W. E., \& Zheng, W. (2008). Alcohol drinking, cigarette smoking, and risk of colorectal adenomatous and hyperplastic polyps. American Journal of Epidemiology, 167(9), 1050-1058. https://doi.org/ 10.1093/aje/kwm400

Siegel, R. L., Miller, K. D., \& Jemal, A. (2015). Cancer statistics, 2015. CA: a Cancer Journal for Clinicians, 65(1), 5-29. https://doi.org/10.3322/caac.21254

Siegel, R., Desantis, C., \& Jemal, A. (2014). Colorectal cancer statistics, 2014. CA: a Cancer Journal for Clinicians, 64(2), 104-117. https://doi.org/10.3322/caac.21220

Sierra-Honigmann, M. R., Nath, A. K., Murakami, C., García-Cardeña, G., Papapetropoulos, A., Sessa, W. C., .. . Flores-Riveros, J. R. (1998). Biological action of leptin as an angiogenic factor. Science, 281(5383), 1683-1686. https://doi.org/ 10.1126/science.281.5383.1683

Slattery, M. L., Boucher, K. M., Caan, B. J., Potter, J. D., \& Ma, K.-N. (1998). Eating patterns and risk of colon cancer. American Journal of Epidemiology, 148(1), 4-16. https://doi.org/10.1093/aje/148.1.4-a

Slattery, M. L., Potter, J., Caan, B., Edwards, S., Coates, A., Ma, K.-N., \& Berry, T. D. (1997). Energy balance and colon cancer-Beyond physical activity. Cancer Research, 57(1), 7580.

Stadler, J., Yeung, K. S., Furrer, R., Marcon, N., Himal, H. S., \& Bruce, W. R. (1988). Proliferative activity of rectal mucosa and soluble fecal bile acids in patients with normal colons and in patients with colonic polyps or cancer. Cancer Letters, 38(3), 315320. https://doi.org/10.1016/0304-3835(88)90023-7

Stattin, P., Palmqvist, R., Söderberg, S., Biessy, C., Ardnor, B., Hallmans, G., . . Olsson, T. (2003). Plasma leptin and colorectal cancer risk: A prospective study in Northern Sweden. Oncology Reports, 10(6), 2015-2021.

Terry, P., Giovannucci, E., Michels, K. B., Bergkvist, L., Hansen, H., Holmberg, L., \& Wolk, A. (2001). Fruit, vegetables, dietary fiber, and risk of colorectal cancer. Journal of the National Cancer Institute, 93(7), 525-533. https://doi.org/10.1093/jnci/93.7.525

Thun, M. J., Calle, E. E., Namboodiri, M. M., Flanders, W. D., Coates, R. J., Byers, T., . . Heath, C. W., Jr. (1992). Risk factors for fatal colon cancer in a large prospective study. Journal of the National Cancer Institute, 84(19), 1491-1500. https://doi.org/10.1093/ jnci/84.19.1491

Thygesen, L. C., Wu, K., Grønbaek, M., Fuchs, C. S., Willett, W. C., \& Giovannucci, E. (2008). Alcohol intake and colorectal cancer: A comparison of approaches for including repeated measures of alcohol consumption. Epidemiology (Cambridge, Mass.), 19(2), 258-264. https://doi.org/10.1097/EDE.0b013e31816339e0

Tollefson, M. K., Elliott, D. S., Zincke, H., \& Frank, I. (2010). Long-term outcome of ureterosigmoidostomy: An analysis of patients with $>10$ years of follow-up. BJU International, 105(6), 860-863. https://doi.org/10.1111/j.1464-410X.2009.08811.x 
Torre, L. A., Bray, F., Siegel, R. L., Ferlay, J., Lortet-Tieulent, J., \& Jemal, A. (2015). Global cancer statistics, 2012. CA: a Cancer Journal for Clinicians, 65(2), 87-108. https:// doi.org/10.3322/caac.21262

Tran, T. T., Medline, A., \& Bruce, W. R. (1996). Insulin promotion of colon tumors in rats. Cancer Epidemiology and Prevention Biomarkers., 5(12), 1013-1015.

Trock, B., Lanza, E., \& Greenwald, P. (1990). Dietary fiber, vegetables, and colon cancer: Critical review and meta-analyses of the epidemiologic evidence. Journal of the National Cancer Institute, 82(8), 650-661. https://doi.org/10.1093/jnci/82.8.650

Vernick, L. J., \& Kuller, L. H. (1982). A case-control study of cholecystectomy and rightside colon cancer: The influence of alternative data sources and differential interview participation proportions on odds ratio estimates. American Journal of Epidemiology, 116(1), 86-101. https://doi.org/10.1093/oxfordjournals.aje.a113405

Vernick, L. J., Kuller, L. H., Lohsoonthorn, P., Rycheck, R. R., \& Redmond, C. K. (1980). Relationship between cholecystectomy and ascending colon cancer. Cancer, 45(2), 392-395. https://doi.org/10.1002/1097-0142(19800115)45:2<392::AIDCNCR2820450234>3.0.CO;2-9

Wang, A., Clouston, S. A., Rubin, M. S., Colen, C. G., \& Link, B. G. (2012). Fundamental causes of colorectal cancer mortality: The implications of informational diffusion. The Milbank Quarterly, 90(3), 592-618. https://doi.org/10.1111/j.1468-0009.2012.00675.x

Wei, E. K., Giovannucci, E., Wu, K., Rosner, B., Fuchs, C. S., Willett, W. C., \& Colditz, G. A. (2004). Comparison of risk factors for colon and rectal cancer. International Journal of Cancer, 108(3), 433-442. https://doi.org/10.1002/ijc.11540

Wei, E. K., Ma, J., Pollak, M. N., Rifai, N., Fuchs, C. S., Hankinson, S. E., \& Giovannucci, E. (2005). A prospective study of C-peptide, insulin-like growth factor-I, insulin-like growth factor binding protein-1, and the risk of colorectal cancer in women. Cancer Epidemiology and Prevention Biomarkers., 14(4), 850-855. https://doi.org/ 10.1158/1055-9965.EPI-04-0661

Will, J. C., Galuska, D. A., Vinicor, F., \& Calle, E. E. (1998). Colorectal cancer: Another complication of diabetes mellitus? American Journal of Epidemiology, 147(9), 816-825. https://doi.org/10.1093/oxfordjournals.aje.a009534

Willett, W. C., Stampfer, M. J., Colditz, G. A., Rosner, B. A., \& Speizer, F. E. (1990). Relation of meat, fat, and fiber intake to the risk of colon cancer in a prospective study among women. The New England Journal of Medicine, 323(24), 1664-1672. https:// doi.org/10.1056/NEJM199012133232404

Wong, R. J. (2010). Marked variations in proximal colon cancer survival by race/ ethnicity within the United States. Journal of Clinical Gastroenterology, 44(9), 625-630. https://doi.org/10.1097/MCG.0b013e3181c64a7a

Zisman, A. L., Nickolov, A., Brand, R. E., Gorchow, A., \& Roy, H. K. (2006). Associations between the age at diagnosis and location of colorectal cancer and the use of alcohol and tobacco: Implications for screening. Archives of Internal Medicine, 166(6), 629-634. https://doi.org/10.1001/archinte.166.6.629 